\title{
Correction to: Preoperative Upper-GI Endoscopy Prior to Bariatric Surgery: Essential or Optional?
}

\author{
Yusef Moulla ${ }^{1,2}$ (D) Orestis Lyros ${ }^{1} \cdot$ Matthias Mehdorn ${ }^{1} \cdot$ Undine Lange ${ }^{1,2} \cdot$ Haitham Hamade $^{1} \cdot$ Rene Thieme $^{1} \cdot$ \\ Albrecht Hoffmeister ${ }^{3} \cdot$ Jürgen Feisthammel ${ }^{3} \cdot$ Matthias Blüher $^{2} \cdot$ Boris Jansen-Winkeln $^{1} \cdot$ Ines Gockel $^{1}$. \\ Arne Dietrich $^{1,2}$
}

Published online: 20 April 2020

(C) Springer Science+Business Media, LLC, part of Springer Nature 2020

\section{Correction to: Obesity Surgery https://doi.org/10.1007/s11695-020-04485-5}

In the original article the name of author Matthias Blüher was incorrect. It is correct here and the original article has been corrected.

Publisher's Note Springer Nature remains neutral with regard to jurisdictional claims in published maps and institutional affiliations.

The online version of the original article can be found at https://doi.org/ 10.1007/s11695-020-04485-5

Yusef Moulla

yusef.moulla@medizin.uni-leipzig.de

1 Department of Abdominal, Transplant, Thoracic and Vascular Surgery, University Hospital of Leipzig, Liebigstrasse 20,

D-04103 Leipzig, Germany

2 Integrated Research and Treatment Center (IFB) Adiposity Diseases, Leipzig, Germany

3 Clinic for Gastroenterology, Department of Internal Medicine,

University Hospital of Leipzig, Liebigstrasse 20,

D-04103 Leipzig, Germany 